\title{
Meet the contributors
}

\author{
Nicola Oberbeckmann-Winter
}

Published online: 14 December 2011

(C) Springer-Verlag 2011

This opening issue of Analytical and Bioanalytical Chemistry for 2012 celebrates the 10th anniversary of Analytical and Bioanalytical Chemistry and highlights current research by the Editors and members of the International Advisory Board. The strong commitment and dedication of the Editors and Advisory Board have been of enormous value in establishing $\mathrm{ABC}$ as an international journal of high rank and standing, publishing innovative research papers from all areas of analytical and bioanalytical science. In preparing this special issue, we are grateful for the overwhelming support we have received and thank the contributors for generously providing thirty-four research papers, nine critical reviews, and seven trend articles from the forefront of their research. Below, we invite you to meet the contributors to this exceptional 10th anniversary issue.

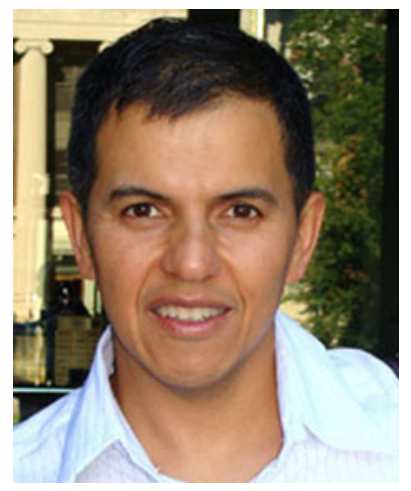

Edgar A. Arriaga

was Fesler-Lampert Chair in Aging Studies from 2007 to 2008 and is currently Professor of Chemistry at the College of Science and Engineering, University of Minnesota, Minneapolis, MN (USA). He is also a graduate of the Faculty of Biomedical Engineering, Gerontology, Molecular Biology, Biochemistry and Biophysics. $\mathrm{He}$ is a chartered member of the National Institutes of Health $(\mathrm{NIH})$ Review Study Section Emerging Biotechnologies. His research program focuses on the development of bioanalytical methods to investigate tissue complexity, single cells, and subcellular compartments. Applications of these methods include determination of the subcellular fate and metabolism of xenobiotics, and investigating subcellular processes associated with the causes of aging.

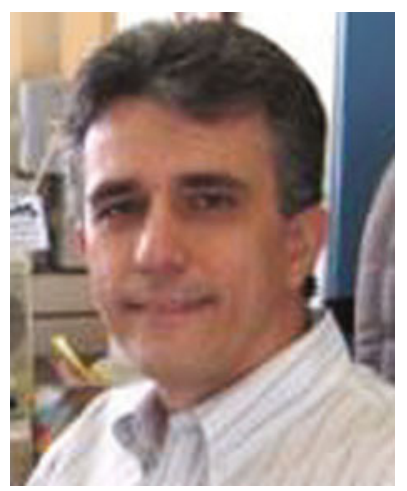

Marco Aurélio Zezzi Arruda

is Full Professor at the University of Campinas-Unicamp, Department of Analytical Chemistry, also belonging to the National Institute of Science and Technology_INCT—for Bioanalysis. The main lines of research of his group includes mass (ICP-MS, LA-ICP-MS, MALDI-QTOF-MS, ESI-MS, TWIMS) and atomic spectrometry (FAAS, TSFF-AAS, ETAAS, ICP-OES), sample preparation, mechanization, and bioanalysis with emphasis on proteomics and metallomics. He is the author or coauthor over 130 research articles and five books, and is on the Editorial Staff or Advisory Board of four journals. His current research interests include trans-disciplinary work involving the comparative omics of plants (i.e. soybean, sunflower) and human body fluids (i.e. blood serum) to identify possible biomarkers for transgenic species and human diseases, and to evaluate reactive oxygen species production, and (metallo)proteins responses under stress in a given system.
N. Oberbeckmann-Winter $(\triangle)$

Analytical and Bioanalytical Chemistry, Springer,

Tiergartenstrasse 17,

69121 Heidelberg, Germany

e-mail: abc@springer.com 


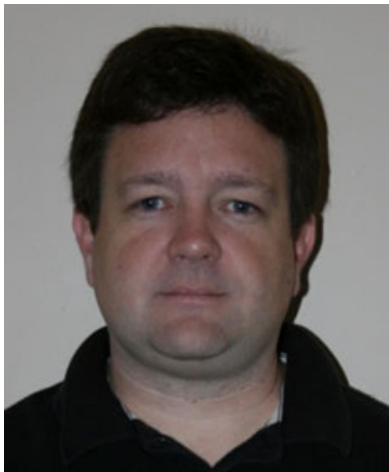

\section{Craig A. Aspinwall}

is an Associate Professor in the Department of Chemistry and Biochemistry at the University of Arizona, where he has been since 2002. His research focuses on the development and application of optical and electrophysiological sensors and microscale separations for the analysis of biological systems. He is a recipient of the ACS Division of Analytical Chemistry Award for Young Investigators in Separation Science (2009) and was an inaugural ACS GREET (Global Research Experiences, Exchanges, and Training) Scholar (2011).

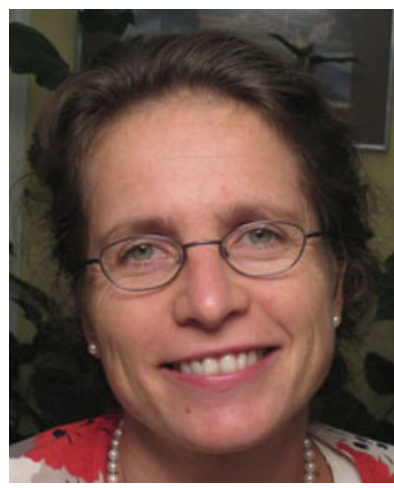

Antje J. Baeumner

is Professor of Biological Engineering and Director of Graduate Studies in the Department of Biological and Environmental Engineering at Cornell University in Ithaca, NY, USA. She is on the Board of Directors of the Society of Electroanalytical Chemistry, a member of the Extended Executive Committee of the International Association of Environmental Analytical Chemistry, was the 2010 Chair of the Gordon Research Conference on Bioanalytical Sensors, and has received numerous honors in recent years including being Finalist for the Blavatnik Award of the NY Academy of Sciences, and recipient of a Humboldt Research Fellowship and a German National Science Foundation Mercator Guest Professorship. Her research is focused on the development of micro-total analysis systems and smart lateral flow assays for detection of pathogens and toxins in food and the environment, and for medical diagnostics.

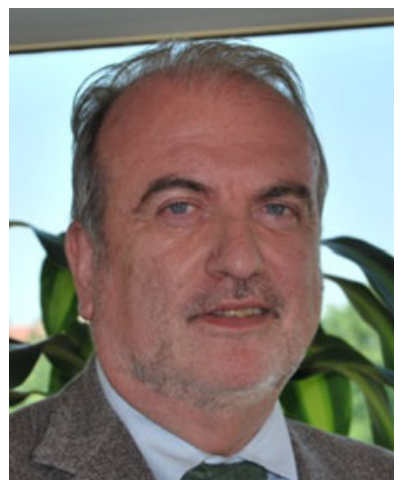

Damià Barceló Cullerés

is Full Research Professor and Deputy Director at IDAEA-CSIC and, since 2008, Director of the Catalan Institute for Water Research (ICRA). From 2009 he has been Visiting Professor at King Saud University, Riyadh, Saudi Arabia. In 2007 he received the King Jaime I Award from the Generalitat of Valencia (Spain) on the Protection of Nature. His research interests are in environmental analysis, and the fate and behavior of organic pollutants in water, sediment, and biota, using mass spectrometric techniques, immunoassay, toxic assays and biosensors. During recent years his interests have also included bridging environment and health risks in the field of emerging contaminants.

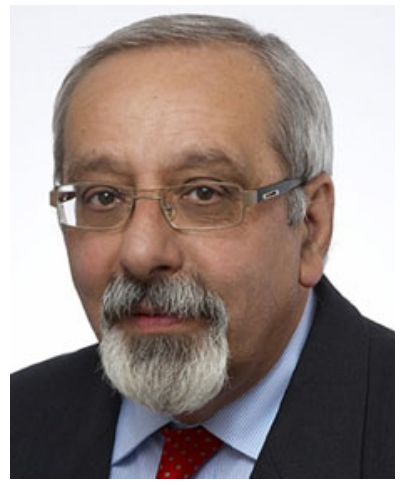

Boguslaw Buszewski

is Head of the Chair of Environmental Chemistry and Bioanalysis at the Faculty of Chemistry, Nicolaus Copernicus University. He serves as President of the Polish Chemical Society, Vice Chair of the Committee of Analytical Chemistry of the Polish Academy of Sciences, and is a member of the Advisory Board of the Austrian Academy of Sciences. Dr Buszewski is president of the European Society for Separation Science (EuSSS). His main scientific interests cover environmental analysis, chromatography, and related techniques (HPLC, SPE, GC, CZE, adsorption, sample preparation), spectroscopy, utilization of waste and sludge, and chemometrics. He is also the chairman of the Central European Group for Separation Sciences (CEGSS), the chairman of the Societas Humboldtiana Polonorum, and member of the Steering Committee of the Division of Environmental Chemistry of the European Association for Chemical and Molecular Sciences (EuCheMS).

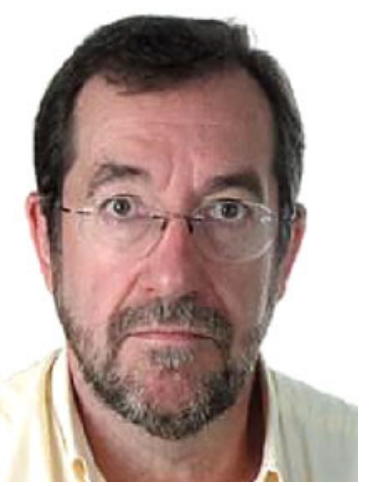

\section{Rafael Cela Torrijos}

is Professor of Analytical Chemistry at the University of Santiago de Compostela, Spain, and the Head of the Laboratory for Analytical Chemistry in the Research Institute of Food Analysis at the same university. Previously, he was at the Universities of Madrid (Complutense) and Cadiz, belonging to the group of analytical chemists that started the development of chemometrics in the 1980s in Spain. His research has focused on the analytical applications of separation science, and, particularly, the development and optimization of sample preparation techniques in chromatographic analysis, including experimental designs and the development of computer-assisted chromatographic methods. He is the author or coauthor of more than 200 scientific papers and several textbooks. 


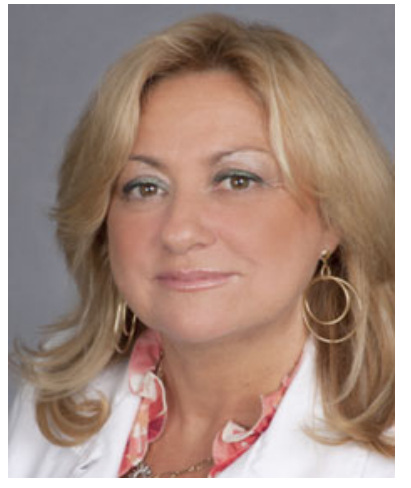

Sylvia Daunert

holds the Lucille P. Markey Chair of Biochemistry and Molecular Biology at the Miller School of Medicine of the University of Miami. Previously, she was the Gill Eminent Professor of Chemistry at the University of Kentucky where she had a secondary appointment in the pharmaceutical sciences. She is a Fulbright Scholar and recipient of numerous awards, for example the A.F. Findeis Award of the American Chemical Society and the special Creativity Award from the National Science Foundation. Dr Daunert's research interests are in bionanotechnology at the interface between analytical biochemistry, molecular biology, and bioengineering. Her group uses recombinant DNA technology to design new molecular diagnostic tools and biosensors, with biomedical, environmental, and pharmaceutical applications, based on genetically engineered proteins and cells. The research also focuses on the design of sensing arrays for detection of molecules in small volumes, by use of microfluidics, and in the development of biomaterials for responsive drugdelivery systems.

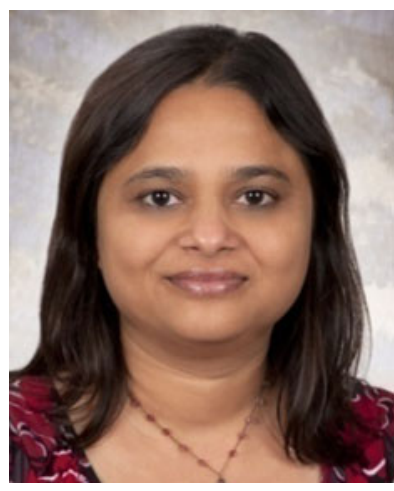

\section{Sapna Deo}

is Associate Professor in the Department of Biochemistry and Molecular Biology at the University of Miami, Miller School of Medicine. Dr Deo's research interest is in the development of novel nanobioanalytical techniques based on luminescence and quantum dots for detection of microRNAs and RNA molecules for application in biomedicine, diagnosis, and pathogen detection. Other areas of research include development of molecular probes for biosensing and bioimaging applications. Her research also focuses on creating luminescent nanocarriers for targeted imaging and sensing applications in biomedicine. She is a author and coauthor of over 70 scientific publications and several patents and a recipient of the NSF-CAREER Award.

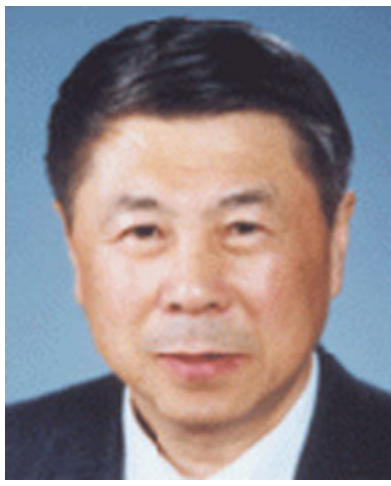

\section{Erkang Wang}

was Director of the Changchun Institute of Applied Chemistry. During his active career he acted as visiting professor in the US, France, Japan, and Hong Kong, and has presented over 150 seminars and keynote lectures in 26 countries. He has published more than 900 papers and monographs in international journals. He is member of various prestigious chemical societies, among others the Japan Society for Analytical Chemistry, the Academy of Sciences for the Developing World, and the Chinese Academy of Sciences. Erkang Wang holds more than ten awards from Chinese national and provincial governments and two international awards. His research interest is focused on analytical chemistry, electrochemistry, electroanalytical chemistry, bioelectrochemistry, and environmental chemistry.

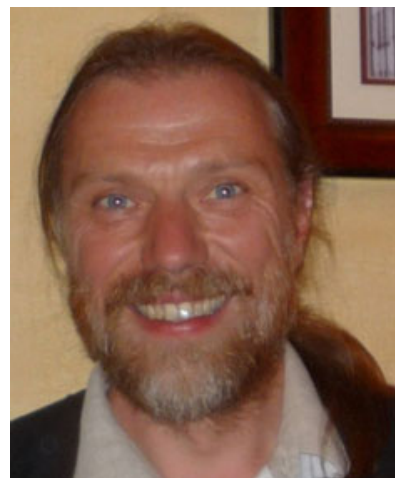

Jörg Feldmann

has held the Chair in Environmental Analytical Chemistry and been Director of TESLA (Trace Element Speciation Laboratory) at the University of Aberdeen (Scotland, UK) for 14 years. $\mathrm{He}$ received his $\mathrm{PhD}$ from the University of Essen (Germany) and was Feodor Lynen Fellow (Alexander von Humboldt Foundation) for two years at the University of British Columbia (Canada). He has pioneered the simultaneous hyphenation of ICPMS and ESI-MS to HPLC for determination of labile metal biomolecule interactions which are crucial to explaining environmental and biological processes. In addition he uses laser ablation ICPMS extensively for bioimaging of elements. He is author or coauthor of more than 150 peer-reviewed publications.

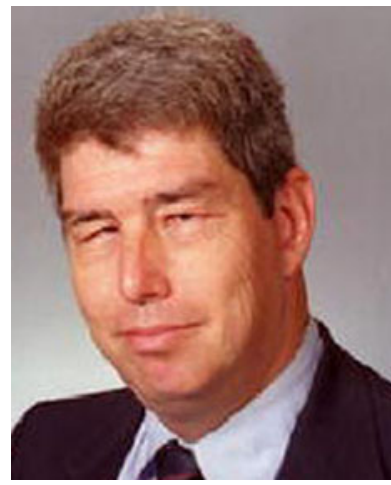

John Fetzer

is author or coauthor of over 130 research articles, reviews, and book chapters. He worked for over 20 years as an analytical chemist for the Chevron Corporation and now runs his own consulting company, Fetzpahs Consulting, in Hercules, CA, USA. He is author of the book Career management for chemists-a guide to success in a chemistry career.

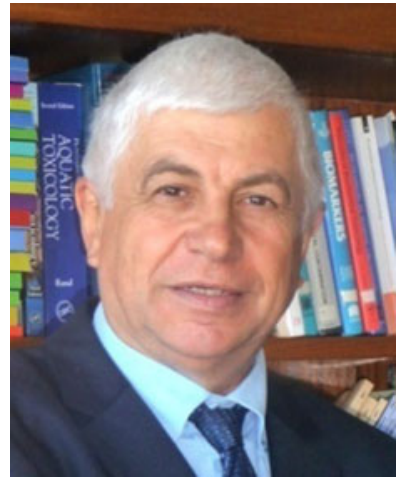

\section{Philippe Garrigues}

is a CNRS Research Director and Head of the Department of Molecular Sciences (CRCM, FR 1981 CNRS) at the University of Bordeaux 1, France, with around 200 researchers involved in a variety of chemistry disciplines (theory, analysis, environment, spectroscopy, synthesis). Dr Garrigues's personal research interests are analytical aspects (chromatography and spectroscopy) of the detection of organic pollutants and their environmental fate and toxicological effects. Recently, he has been involved in the development of biochemical markers as early warning systems for the toxicological evaluation of ecosystems by coordination of large research projects (i.e. BIOMAR, BEEP) supported by DG Research (European Commission, Brussels). 


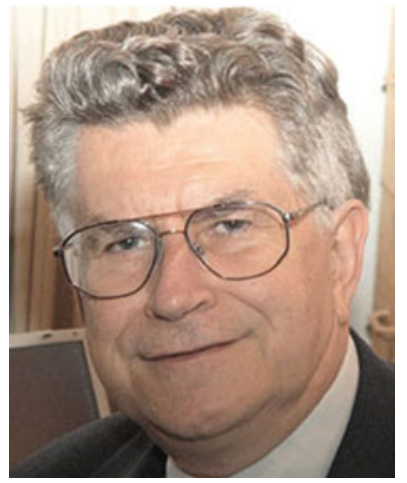

\section{Günter Gauglitz}

is Professor at the Eberhard-KarlsUniversity of Tübingen working in analytical and physical chemistry. $\mathrm{He}$ was chairman of the GDCh Division of Analytical Chemistry and chaired the Europt(r)ode VIII meeting. He is also member of the DAC in EuCheMS. For the last 10 years his main scientific interests have centered on research on and development of chemical and biochemical sensors with special focus on characterization of the interfaces of polymers and biomembrane surfaces, spectroscopic techniques, use of spectral interferometry to monitor changes in optical thickness of thin layers, and the effects of Fresnel reflectivity at interfaces.

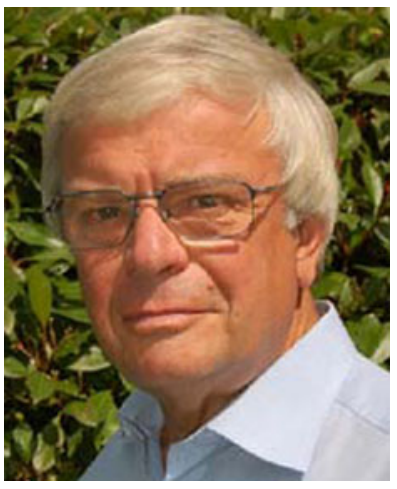

Klaus Gustav Heumann

is Emeritus Professor of Analytical Chemistry at the Johannes Gutenberg University Mainz. His research interests lie in the development and application of analytical methods for the determination of trace elements and trace amounts of elemental species, using inductively coupled plasma mass spectrometry, thermal ionization mass spectrometry, different types of optical atomic spectrometry, and electroanalysis as detection methods, and high-performance liquid chromatography, capillary electrophoresis, and capillary gas chromatography as separation methods. He has received several awards, including the Clemens Winkler Medal of the German Society for Analytical Chemistry in 2004 for his scientific lifework and for continuous support of analytical chemistry in Germany. In 2007 he received the European Award for Plasma Spectrochemistry. He is a member of several national and international scientific societies and he was a member of the IUPAC Commission on Atomic Weights and Isotopic Abundances for 12 years and chairman from 1991 to 1995.

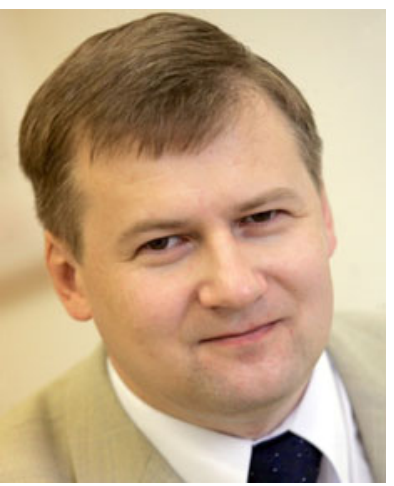

\section{Jiří Homola}

is Head of the Photonics Division and Chairman of the Department of Optical Sensors at the Institute of Photonics and Electronics, Prague (Czech Republic). He also is Affiliate Professor at the University of Washington, Seattle (USA) and Associate Professor at Charles University in Prague (Czech Republic). His research interests are in photonics and biophotonics, in particular in optical sensors and biosensors. J. Homola is a recipient of the Roche Diagnostics Prize for Sensor Technology and Premium Academiae. the environmental fate of chemicals. Since 2009, Dr Giger has chaired the Division of Chemistry and the Environment of the European Association of Chemistry and the Environment of the European Association of Chemical and Molecular Sciences (EuCheMS).

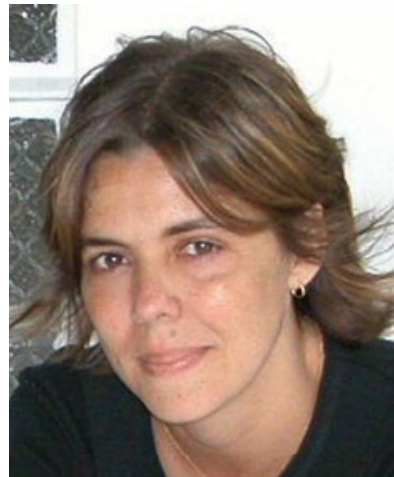

\section{Heidi Goenaga-Infante}

is Principal Scientist at LGC, UK. Her research interests lie in trace element speciation analysis, metallomics research, combined use of elemental and molecular mass spectrometry, size-based element fractionation and the development of reference methods for characterization of "speciated" reference materials and standards. Dr Goenaga-Infante is the UK representative at the Inorganic Analysis Working Group of the CCQM, the international Consultative Committee for Metrology in Chemistry.

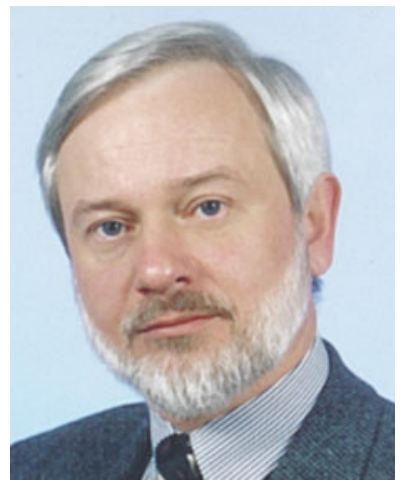

\section{Maciej Jarosz}

is Chair of Analytical Chemistry at the Faculty of Chemistry, Warsaw University of Technology, Poland, Vice-President and treasurer of the Board of the Polish Chemical Society, member of the Board of the Committee on Analytical Chemistry, Polish Academy of Sciences, National Representative in the Division of Analytical Chemistry of IUPAC, and member of the Steering Committee of the Division of Analytical Chemistry of EuCheMS. He is author or co-author of 83 original papers and chapters in monographs. His scientific interests focus on cultural heritage preservation (identification of natural products in art works); food and pharmaceutical analysis, and environmental speciation analysis. He was awarded (among others) the Honored Award of the Polish Chemical Society and the Professor Andrzej Waksmundzki Medal - Committee on Analytical Chemistry, Polish Academy of Sciences Award. 


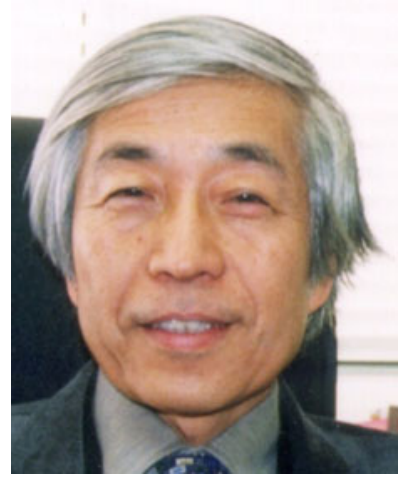

\section{Kiyokatsu Jinno}

is currently trustee and Vice-President of Toyohashi University of Technology, Toyohashi, Japan. His major research interests are in molecular recognition in chromatography, retention mechanisms in liquid chromatography, design of novel stationary phases, miniaturized sample preparation processes with newly designed materials, and their combination for liquid phase separations, development of capillary separation techniques, hyphenated techniques in chromatography, and spectroscopy and computer networking in the separation sciences. He has received several awards for his contributions to chromatography and related analytical techniques: the Tokai Chemical Industry Award in 1986, the Russian Tswett Medal in 1996, the University of Helsinki Medal in 1998, the Golay Award in 1999, the Society Award from the Japanese Society for Chromatographic Sciences in 2000, and the Society Award from the Japan Society for Analytical Chemistry in 2003.

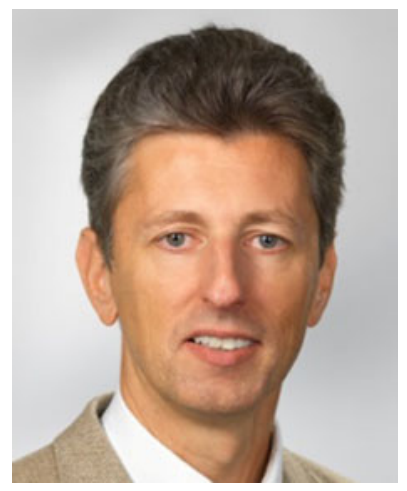

Rudolf Krska

is Full Professor of (Bio)Analysis and Organic Trace Analysis at the University of Natural Resources and Life Sciences, Vienna (BOKU) and Head of the Department of Agrobiotechnology (IFATulln) at BOKU. Rudolf Krska, who is also Head of the Center for Analytical Chemistry at the IFA-Tulln, is an expert in food and feed analysis by chromatographic, mass spectrometric, and immunoanalytical techniques. He has established intensive interdisciplinary cooperation with universities and companies and has been coordinator and work package leader of several European Commission-funded projects dealing with the determination of mycotoxins and allergens in food. As member of JECFA (Joint Expert Committee for Food Additives) of the FAO/WHO he has evaluated the affect of trichothecenes on humans. Dr Krska is also involved in other international activity, for example two working groups of the European Committee for Standardization.

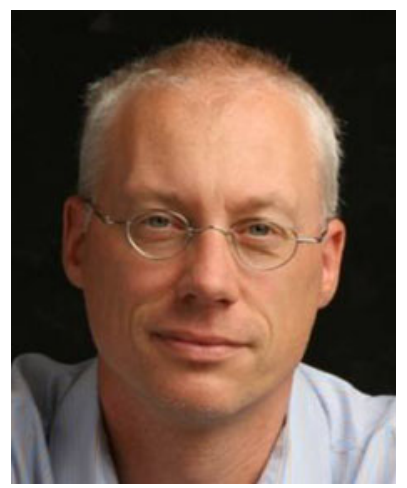

\section{Bernhard Kuster}

is a chemist by training and obtained his $\mathrm{PhD}$ in Biochemistry at the University of Oxford, UK. After post-doctoral terms at the EMBL in Heidelberg and Odense University, Denmark, he worked in the biotechnology firm Cellzome for seven years where he held a number of senior research positions. Professor Kuster currently holds the Chair for Proteomics and Bioanalysis at the Technische Universität München and is also head of the department for Biosciences at the TUM. His research interests include chemical biology, cancer drug discovery, and development of technology for proteomics and mass spectrometry. Professor Kuster has published more than 60 papers which have collected over 8,000 citations and he has won awards from the German Society for Mass Spectrometry, the German Academic Exchange Service, and the European Molecular Biology Organisation.

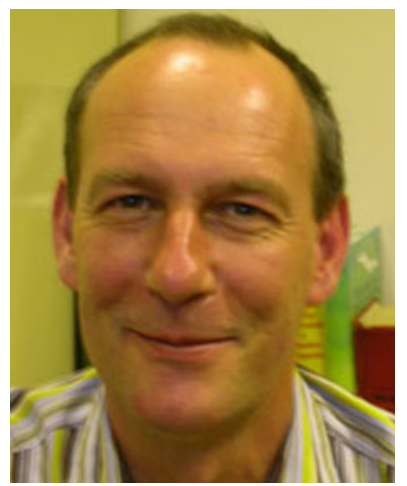

Olivier Laprévote

is currently Professor of Toxicology at the University Paris Descartes (Faculty of Pharmacy) and at Lariboisière Hospital in Paris. He was Group Leader of the Mass Spectrometry Laboratory of the Institute for Natural Compounds Chemistry at Gif-sur-Yvette (France) until 2008. His scientific interests are in the development of original mass spectrometric methods for characterization of natural molecules in complex biological matrices. Among his past research activity, mass spectrometry imaging was prominent, with a particular interest in biomedical applications. 


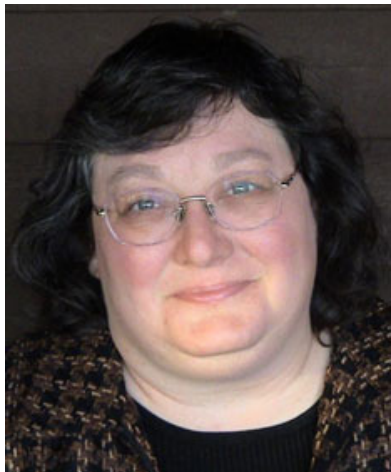

Cynthia Larive

is Professor of Analytical Chemistry at the University of California, Riverside. Dr Larive's research in bioanalytical chemistry focuses on the structural characterization of carbohydrates and plantbased metabolomics. She has an active research program involving bioanalytical and environmental analytical applications of NMR spectroscopy. Professor Larive is also active in curricular reform and promotion of undergraduate research. She is editor-in-chief and principal investigator of the Analytical Sciences Digital Library (http://www. asdlib.org), an Internet-based resource for instructors, students, and practitioners of analytical chemistry. This digital library is a collection of peer-reviewed web sites on topics including pedagogical approaches, analytical techniques, applications, and classroom resources.

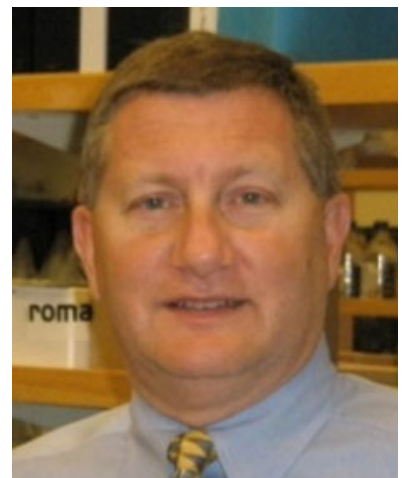

R. Kenneth (Ken) Marcus

is Professor of Analytical Chemistry at Clemson University. Professor Marcus' research program covers three distinct lines of study: the use of capillarychanneled polymer $(\mathrm{C}-\mathrm{CP})$ fibers and films for protein separations; the use of particle beam LC-MS for profiling botanical products (nutraceuticals); and the development of liquid sampling-atmospheric pressure glow discharge (LS-APGD) microplasmas for spectrochemical analysis. In 2010 he was honored by election to Fellowship of the Royal Society of Chemistry.

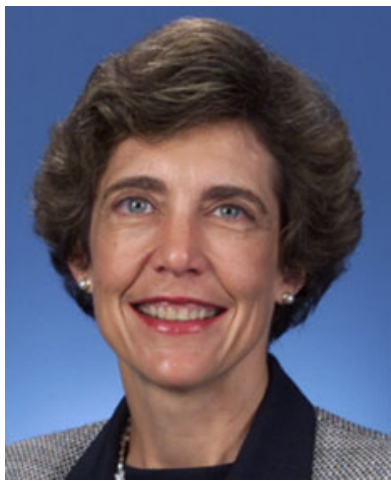

\section{Frances S. Ligler}

is the Navy's Senior Scientist for biosensors and biomaterials and a member and past chair of the Bioengineering Section of the US National Academy of Engineering. She has over 350 full-length publications and patents $(>7,000$ citations), which have led to eleven commercial biosensor products and won her the Homeland Security Award (Biological, Radiological, Nuclear Field) of the Christopher Columbus Foundation and the Presidential Rank of Distinguished Senior Professional awarded by President Bush.

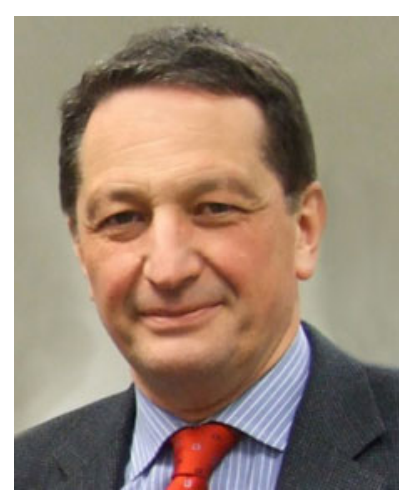

Hans H. Maurer

is Head of the Department of Experimental and Clinical Toxicology of the Saarland University in Homburg (Saar). He has published over 200 original papers and 30 invited reviews on his main two areas of research, analytical toxicology (GCMS, LC-MS) and metabolism of xenobiotics. He has received several international scientific awards, and in 2007 he was awarded the title of Doctor Honoris Causa by the University of Ghent, Belgium.

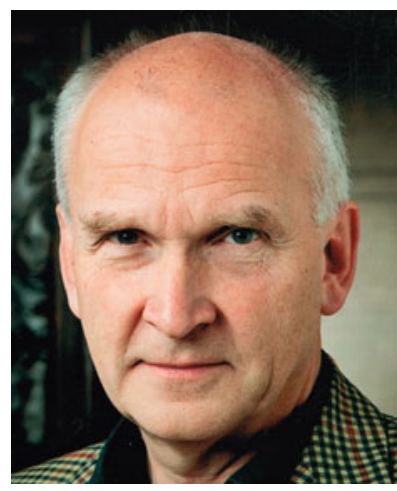

\section{Wolfgang Lindner}

is expert in separation sciences with focus on life-science analysis and material science, developing diverse stationary phases with dedicated selectivity properties. Among these the chiral stationary phases became the most widely known. Since 1996 Wolfgang Lindner has held the Chair of Analytical Chemistry at the University of Vienna, Austria. He is author and coauthor of more than 400 publications. Among other prizes, he has received the Chirality Medal, the A.J.P. Martin Gold Medal, the Halasz Medal, and, very recently, the ACS Award for Chromatography.

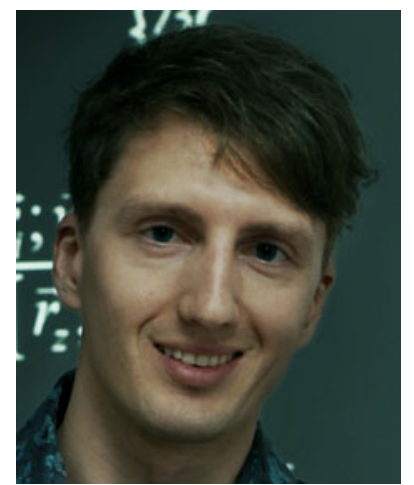

Juris Meija

is a Research Officer at the Institute for National Measurement Standards, National Research Council, Canada. His research interests encompass theoretical analytical chemistry, isotope ratio measurements, and the history of chemistry. He serves as Column Editor for the Analytical Challenge series in Analytical and Bioanalytical Chemistry and is the Secretary of the IUPAC Commission on Isotopic Abundances and Atomic Weights. 


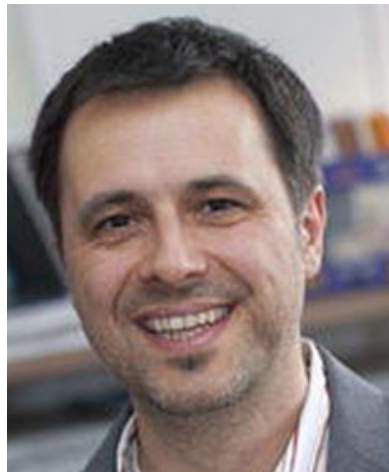

\section{Boris Mizaikoff}

is currently Chaired Professor and Director of the Institute of Analytical and Bioanalytical Chemistry at the University of Ulm, Germany. He is also a member of the Center for Cell and Molecular Signaling at Emory University, Atlanta, GA, USA. His research interests focus on optical sensors, biosensors, and biomimetic sensors operating in the mid-infrared spectral range, quantum cascade lasers, system miniaturization and integration based on micro and nanofabrication, multifunctional (nano)analytical technology, focused ion-beam techniques, development of chemical recognition layers for separation and sensing applications, environmental and process analysis, and biomedical diagnostics.

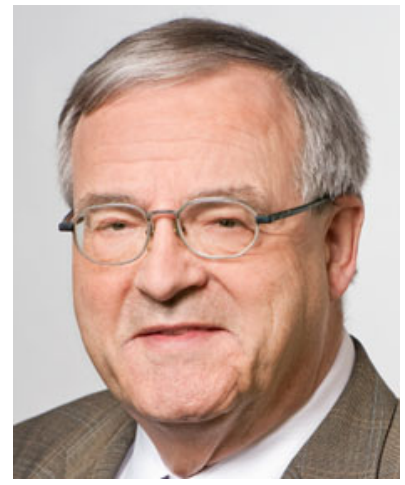

Reinhard Nießner

is Full Professor of Analytical Chemistry at the Technical University of Munich. His research interests are in environmental analytical chemistry, especially devoted to applications of laser spectroscopy, nanoparticle characterization, and microarray technology. His main areas of interest are aerosols, hydrocolloids, and biofilms, in the water and atmosphere. He has received several international awards, e.g. the Emanuel-Merck Prize for Analytical Chemistry (1990), the Smoluchowski Award for Aerosol Research of the Association for Aerosol Research (1991), the Fritz-Pregl Medal of the Austrian Society for Analytical Chemistry (1996), and the Fresenius Award for Analytical Chemistry of the German Chemical Society (2000). Professor Nießner has served in many national and international scientific organizations, e.g. within IUPAC as a Titular Member and the European Science Foundation.

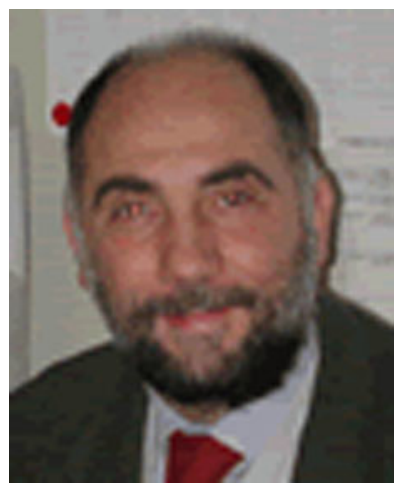

\section{Giuseppe Palleschi}

is Full Professor of Analytical Chemistry and was Head of the Department of Chemical Science and Technology of the University of Rome "Tor Vergata" between 1995 and 2007 In the 2000 he obtained the "Laurea Honoris Causa" from the University of Bucharest for his activity in the field of chemical sensors for food and environmental control. Professor Palleschi's research over the last 30 years has been focused on the development of chemical sensors and bio and immunosensors for use in biomedicine, food and environmental analysis. He is the author of more than 200 papers in international scientific journals and invited speaker at many International Congresses. He has been visiting scientist for two years in the USA (University of New Orleans), for three months in the UK (University of Cranfield), and one month at RCAST (Japan).

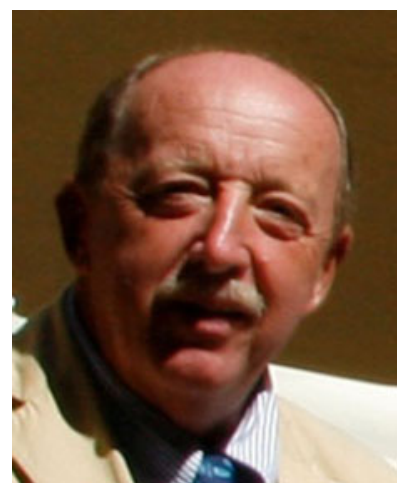

\section{Aldo Roda}

is Professor of Analytical Chemistry at the Alma Mater Studiorum University of Bologna, Italy. He is Vice-President of the Italian Society of Chemistry ("Società Chimica Italiana", SCI) and a member of the Academy of Science, Institute of Bologna. His main research interests center on the development of devices, cellular biosensors, and ultrasensitive analytical methods and imaging based on chemi-bioluminescence applied to clinical chemistry, medicinal chemistry, environmental chemistry, cultural heritage, and food analysis. $\mathrm{He}$ is co-author of more than 400 articles published in international journals, and 24 international patents on new bile acids, antioxidant drugs, new luminescent labels, biosensors, and luciferase probes. 


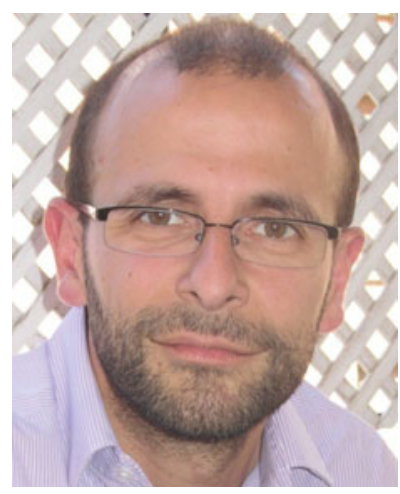

\section{Jorge Ruiz Encinar}

has been Associate Professor at the University of Oviedo (Spain) since 2010. His research interests are mass spectrometry and stable isotope-based methods, mostly applied to environmental science, speciation, and heteroatom-tagged proteomics, and the development of new biological applications of functionalized nanoparticles. In 2007 he was awarded the "Young Chemist Prize" by the Spanish Royal Society of Chemistry. He is currently the coordinator of the International Master in Analytical and Bioanalytical Sciences at the University of Oviedo (dual diploma with the University of Pau, France).

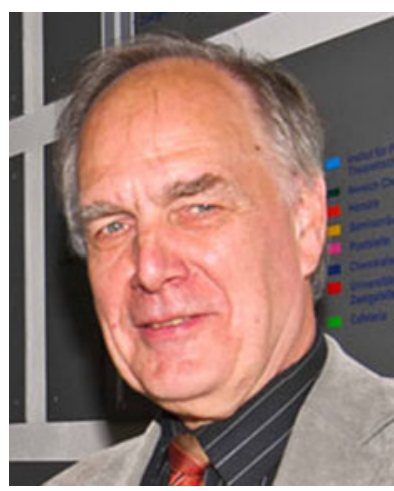

\section{Reiner Salzer}

retired as Professor of Analytical Chemistry at the Technische Universität Dresden, Germany, in 2007. His main scientific interests include molecular monitoring for early diagnosis of diseases, integration of biologically active functions into polymers, and electronic media in university education. Professor Salzer has authored 14 patents in different fields of analytical chemistry, and over 250 books and scientific publications. Professor Salzer has been elected on to a variety of national and international boards. He is a member of the Norwegian Academy of Science, a recipient of the Emich Plaque of the Austrian Society of Analytical Chemistry (2007) and of the Clemens Winkler Medal of the Division Analytical Chemistry of the German Chemical Society (2011). He served as President of the Division Analytical Chemistry of the German Chemical Society, and is National Delegate to the Division of Analytical Chemistry of EuCheMS, where he is Head of the Study Group Education. He is ViceChairman of the ECTNA Label Committee for the Chemistry Eurobachelor and Chemistry Euromaster and is currently involved in the development of a quality scheme for a Eurodoctorate label.

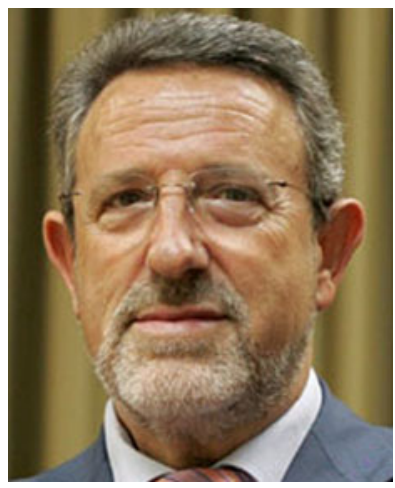

\section{Alfredo Sanz-Mede}

has been Professor in the Department of Physical and Analytical Chemistry of Oviedo University (Spain) since 1982. He is author or co-author of approximately 500 scientific publications in international journals, several patents, and books. His current research interests include new atomic detectors and ion sources for ultratrace analysis using plasmas, new molecular optical sensors, particularly those based on the use of quantum dots, and hybrid techniques, coupling a separation unit and an atomic detector for ultra-trace and trace metal speciation to solve biological and environmental problems, and speciation for proteomics. The objective of this work is to integrate mass spectrometry (MS), "molecular" (matrix-assisted laser desorption/ionization and electrospray MS), and "atomic" (inductively coupled plasma (ICP)MS) techniques, and introduction of the extensive use of ICP-MS to carry out "heteroatom-tagged proteomics", for both qualitative and quantitative purposes. At Euroanalysis 2007, in Antwerp, he received the Robert Kellner Award. In 2011 he was granted the European Award of Plasma Spectrochemistry.

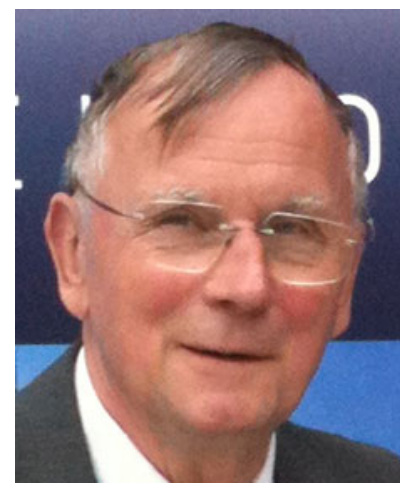

Frieder W. Scheller

is Visiting Professor at University of Potsdam and consultant at the Fraunhofer IBMT. For many years he headed the Department of Bioelectrochemistry/Biosensors at the Central Institute of Molecular biology of the German Academy of Sciences, Berlin-Buch. In 2001 he was President of the German Society of Biochemistry and Molecular Biology. He has been working on the development of biosensors for more than 30 years. At present his research interest is focused on bioelectrocatalysis and molecularly imprinted polymers.

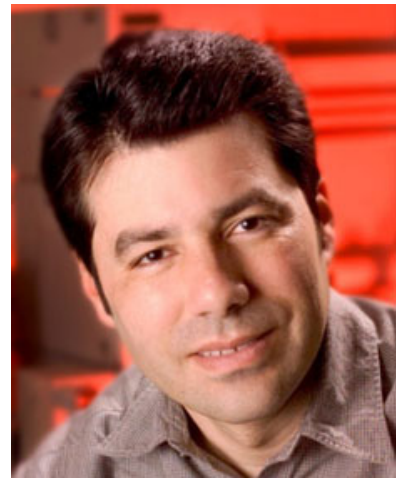

\section{André M. Striegel}

is a Research Chemist at the National Institute of Standards and Technology (NIST). He was previously Assistant Professor of Analytical and Materials Chemistry at Florida State University (FSU) and, before that, Research Specialist at Solutia Inc. He was the inaugural recipient of the ACS-DAC Award for Young Investigators in Separation Science and inaugural Professor in Residence for Preservation Research and Testing at the US Library of Congress. He is also the recipient of an Eli Lilly Analytical Chemistry Grantee Award, an FSU First Year Assistant Professor Award, and a Solutia Technical Achievement Award. His main research interests are in separation science of macromolecules.

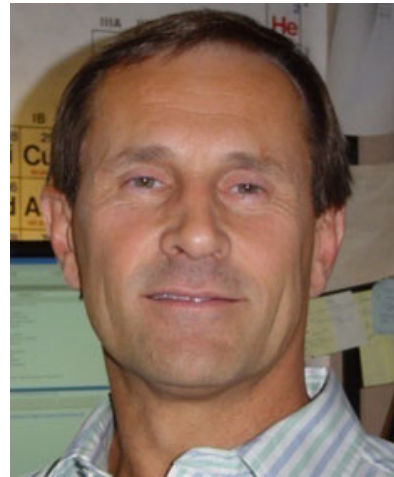

Ralph Sturgeon

is Principal Research Officer in the Chemical Metrology Group of the Institute for National Measurement Standards, National Research Council, Canada. His interests lie in inorganic analytical chemistry, including trace element analysis, vapor generation, organometallic speciation, and production of certified reference materials with a focus on atomic and mass spectrometric detection. 


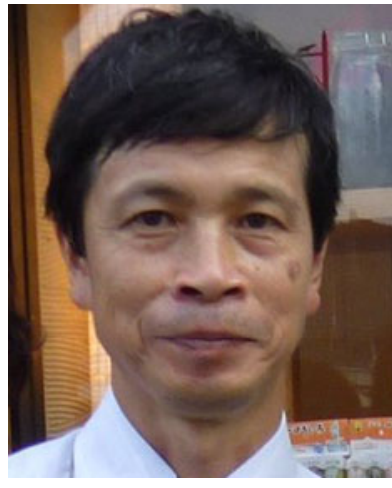

Toyohide Takeuchi

is Professor of Chemistry at the Faculty of Engineering, Gifu University, Japan. He received a Bachelor's degree in engineering (1977), a Master's degree in engineering (1979), and a Doctorate in engineering (1985) from Nagoya University. He was appointed Research Associate (1980) and Associate Professor (1989) at Nagoya University, and joined Gifu University as Associate Professor in 1992, where he was promoted to Professor of Chemistry in 2001. During 1985 and 1986 he was appointed postdoctoral fellow at Ames Laboratory in USA. His research interests include the development of capillary columns, and novel detection and separation systems for capillary LC. He is author or co-author of approximately 240 original papers. He received the Japan Society for Analytical Chemistry Award for Young Scientists in 1987, the Takeda Techno-Entrepreneurship Award in 2001, and The Society for Chromatographic Sciences Award in 2004.

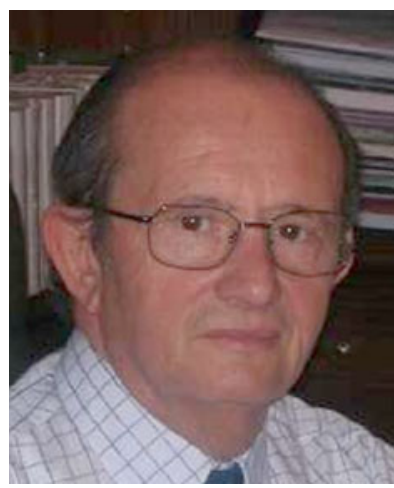

\section{Miguel Valcárcel Cases}

has been Full Professor of Analytical Chemistry at the University of Córdoba since 1976 . He is author and co-author of 800 scientific articles, seven monographs, eight textbooks, and sixteen chapters of books. He has been the coordinator of 25 Spanish scientific research projects and 14 of international nature, and of 12 contracts with private firms, and has promoted a spinoff devoted to nanotechnology. Professor Valcárcel has been co-supervisor of 68 doctoral theses and invited lecturer at 70 international meetings. He is the recipient of scientific national (e.g. Award in Chemistry in Spain, 2006) and international (e.g. Robert Boyle Medal of the RSC, 2004) prizes as well as Doctor Honoris Causa by the University of Valencia (Spain).

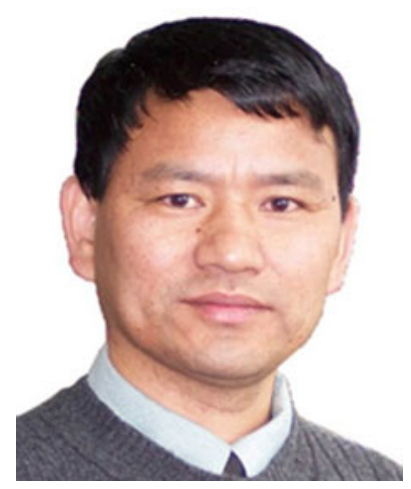

Weihong Tan

obtained his PhD in Physical Chemistry in 1993 at the University of Michigan and is currently V.T. and Louis Jackson Professor of Chemistry. His research interests are in molecular engineering, bioanalysis, bionanotechnology, and chemical biology. His group has engineered nucleic acid probes for biosensing and DNA nanomotors. The Tan group has also developed numerous bioconjugated nanostructures, for example silica nanoparticles, for molecular imaging, cell separation, and sensitive analytical detection. With the development of cell-based SELEX, they have generated a variety of aptamers for cancer cells as molecular tools for early cancer detection, targeted treatment, and biomarker discovery.

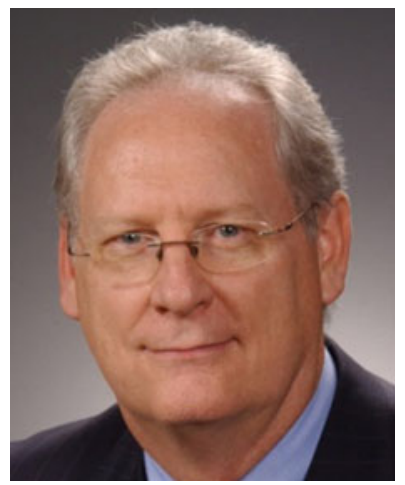

Stephen A. Wise

is Head of the Analytical Chemistry Division at the National Institute of Standards and Technology (NIST). Dr Wise's research efforts focus on the development of certified reference materials for trace organic constituents in environmental, clinical, food, and dietary supplement matrices; development of chromatographic methods for organic analysis; and investigations of chromatographic separation mechanisms and chromatographic selectivity. $\mathrm{He}$ has served as Chairman of the Division of Analytical Chemistry of the American Chemical Society (1996) and as President of the International Society of Polycyclic Aromatic Compounds (2003-2005). He received the 2001 Polycyclic Aromatic Hydrocarbon Research Award presented by the International Society of Polycyclic Aromatic Compounds (ISPAC) and the 2006 Harvey W. Wiley Award from AOAC International.

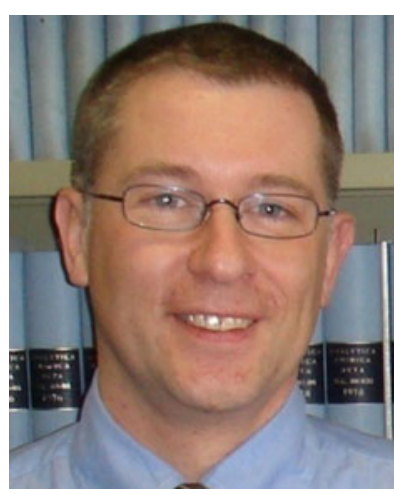

Frank Vanhaecke

is Professor of Analytical Chemistry at Ghent University (Belgium) where he leads the "Atomic and Mass Spectrometry-A\&MS" research group. Prof Vanhaecke has a passion for the determination, speciation, and isotopic analysis of (trace) elements by ICPmass spectrometry (ICP-MS). He is an author of approximately 170 papers in peer-reviewed international journals and several book chapters. In 2011, he received a "European Award for Plasma Spectrochemistry".

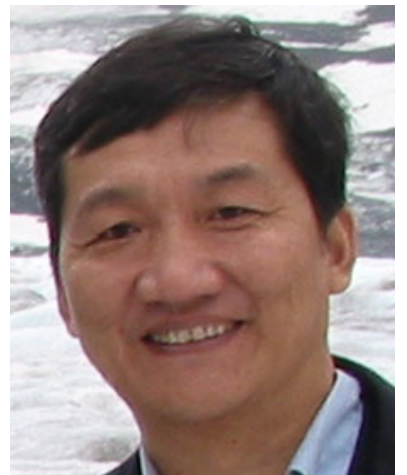

Xinrong Zhang

received his Bachelor's and Master's degrees in chemistry from Shaanxi Normal University, China, and Ph.D. degree in analytical chemistry from University of Ghent, Belgium. He was appointed Professor of the Department of Chemistry, Tsinghua University, China, in 1997. His current research interests are focused on developing optical and mass spectrometric techniques for biomedical and environmental analysis. He published over 170 papers and several book chapters (in English) on these topics. 